\title{
Analysis of posture and its impact on performance in women's water polo
}

\begin{abstract}
Purpose: The study examines the postural effects on the wellness and the performance of fourteen professional female water polo athletes. There are no written studies on water polo, probably because it is assumed that there is no pain because Archimedes's formula opposes the force of gravity. Currently athletes carry out exercises to compensate and to avoid any eventual pain that then disappears when they are out of the water according to motor control and learning theory. The aim is to understand the phenomenon in professional athletes using a tridimensional analysis of the surface of the torso and the baropodometric platform.
\end{abstract}

Methods: This consists in examining the "3D" surface of the torso of fourteen professional water polo athletes, and the data of the baropodometric platform. This data highlights curves that will then be considered with regards to athletic performance and well being. The data of performance and well being of the athletes is collected by a trainer for each single athlete. The study was carried out at the specialized center CORPORA of Gricignano (CE) with the following apparatus: "Formetric Spinometer". The postural Formetric check-up supplies a series of indicators which together give a detailed evaluation of the subject's posture. For each athlete, a summary chart was processed, showing a 3D reconstruction of the surface of the torso and the individualization of specific postural parameters with the data collected by the trainers on the athlete's performance and well being. This data was elaborated using a statistic model of linear regression

Results: The evaluation of the data did not reveal that there is no correlation between pseudo pathological curves and sports performance, whereas athletes with a perfect exam often complained of pain

Conclusions: There is a paradox regarding affection, performance and pain; in some cases it is low, while in some cases, it is the opposite It is to consider that these athletes carrying their water activities are subject to the principle of Archimedes
Volume I Issue 3 - 2017

\author{
Salvatore Napolitano, Antonio Ascione \\ Department Physical Education and Wellness (M-EDF/02), \\ University of Naples Parthenope, Italy
}

\begin{abstract}
Correspondence: Salvatore Napolitano, Department Physical Education and Wellness, University of Naples Parthenope, Italy, Email salvatore.napolitano2013@gmail.com
\end{abstract}

Received: July 06, 2017 | Published: October 12, 2017

Keywords: spinometria formetric, postura, performances

\section{Introduction}

This study has analyzed the effects of postural aspects on the state of well being and performance of 14 high level water polo athletes. ${ }^{1}$ The tri dimensional analysis of the surface torso and the baropodometric platform supplied specific data collection that was useful to better understand the effects that posture has in sports performance, and especially on the capability of the athlete's body to modify and correct posture in order to compensate the presence of any eventual pseudo pathological curves. The Formetric data collecting method is the most widespread in the world, offering a tridimensional optic system screening of the spinal cord and posture. Data on morphological appearance of the athletes were detected thanks to Spinometro Formetric Diers, an optical analysis system of the spine, designed in Germany thanks to a project of the European Community (for screening and the study of scoliosis in children to prevent risks related to 'high number of exposures to x-rays), and spread throughout the world in major centers dedicated to spinal pathologies. ${ }^{2}$

It 'the first system designed to perform the analysis of posture and three-dimensional morphology of the back method with NonInvasive and Non-ionizing. The Formetric system offers a non invasive screening system and an extensive optical scan of the vertebrae (for a static image screening, with a time of 40 milliseconds to exclude the effects caused by spontaneous postural variations), whit the possibility to graphically represent numerous problems of clinical nature inherent to objective analysis and in quality of corporal statics and posture, scoliosis and of all the possible alterations of the spinal cord. The morphological screening system of the spinal cord automatically collects the points $(\mathrm{C} 7$, sacrum, lumbar), the meridian line and the rotation of the vertebrae. The result is the creation of a tri dimensional model of the spinal cord, or rachis, in its entirety, representing morphological rotation and positioning of the pelvis. ${ }^{3}$

Thanks to numerous possible uses, the spinometer is particularly useful to: screening programs for children;

I. Analysis and monitoring of scoliosis patients, with the advantage of avoiding radiological exams as a first means of testing.

II. Measuring, analysis and monitoring of patients affected by lordosis.

III. planning and verifying medical supplies, such as conventional prosthesis, insoles for proprioceptive correction, dental braces

IV. therapeutic support and intervention and control of results obtained $^{4}$ 


\section{V. control, quality verification and documentation in rehabilitation}

VI. Legal medicine evaluation, for example, cervical distortion trauma.

The functional principle of Formetrics is based on triangularization. The active triangularization techniques allow the collection of the surface of a specific object through a luminous source, illuminated at a determined angle, and a video camera which captures the light reflected from it. Considering a point, the three lines constituted by the congruent illuminated line source video camera, the ray of light of the object and light source, and from the rays of light reflected by the object and video camera, a triangle is derived (hence the origin of the name of the technique). When we know the direction of light and the distance of the video camera light source it is possible to calculate the distance separating the object (pt) from the video camera. Carrying out such a procedure through projection of parallel light bands (raster image), it is possible to carry out $3 \mathrm{D}$ superficial data with great precision $^{5}$ (up to $0,01 \mathrm{~mm}$ ). Such a technique is defined top metric projection of bands or video raster stereography.

As a result we individualize the coordinates of the relative pixels to each point of the object's surface "hit" by a band of light; the density of the scan results directly proportional to the density of the luminous bands. However, if they are too high, problems may occur during data processing. Results are available under form of 3D coordinates in which the values depend on the casual position of the patient with respect to the system of image acquisition, with points distributed on the skin's surface in a regular way. The reference points allow various measures and unvaried corporal comparison, rather independently from the position of the subject with respect to image acquisition. Such anatomical points are VII cervical vertebrae, right and left lumbar and the symmetrical line. The symmetrical line of the subject with ideal posture coincides with the median line of the body and the saggital median planne, and can be considered coincidental with the spinal process line. Given the existing correlation among the superficial reference points and the bone structure, it is possible to build a highly precise tridimensional model and derive reliable evaluation parameters. ${ }^{6}$ The morphological evaluation passes through the following phases:

a. Automatic localization of spinal cord process line through calculation of symmetrical line;

b. Measurement of the superficial rotation with respect to the spinal process lines and vertebral rotation measurement;

c. Localization of the center of the vertebrae through evaluation of the anatomical dimensions.

d. Few seconds after the measurements are taken the examiner will have the following information.

e. Saggital profile of the dorsal structure and the spinal cord

f. Lateral frontal deviation of the spinal cord

g. Transversal superficial and vertebral rotation

h. Complex tridimensional view of the spinal cord.
Other instruments that aid in postural examination are the baropodometric platform and stabilometry. The baropodometric platform is surely a cutting edge instrument in the study of the foot. It consists in a platform with applied sensors which are connected to a computer system. What the system measures are the reactions on the ground, in an exact position and in motion. The findings and measurements collected during the exam are printed with color "photographs" in which an automatic analysis of the pressure values and their comparison to normal parameters. Through the barapodometric exam, various parameters are seen. The correct interpretation of this data allows you to precisely evaluate the general attitude of toned posture in the subject with respect to measurements collected in the norm. The collection of data is precise, instantaneous, repeatable, non invasive and allows the reduction of radiological exams. The stabilometric analysis (posturography) can be carried out be the same baropodometric platform because it is able to function as a stabilizer and measure the postural movements in static position.

\section{Methods}

The research method experimented in evaluating the 3D data collection is that of the torso of 14 water polo athletes who participated in the Italian Championships in the A1 series. Such evaluation had the goal to reveal the state of their spinal cord and highlight any eventual pathological curves and their consequences on both their athletic ability and their health. The exam was carried out at the CORPORA Center of Gricignano (CE) with "Formetric Spinometry" equipment. "Formetric Spinometry" allows you to carry out tridimensional morphological data collection of the torso with extreme accuracy, this allows the morphological 3D image of the torso, with extreme accuracy speed (few minutes per procedure), ${ }^{7}$ and safety thanks to the radiation like traditional radiological (does not imply ionized radiation) exams free equipment (with a margin of error inferior to $0,02 \mathrm{~mm}$ ). The Formetric postural check up supplies a series of indicators which together allow you to obtain a detailed evaluation of the subject's posture and complete the clinical examination with various elements. It was possible to carry out such research tank to the cooperation of the CORPORA center (which provided the equipment) and the Volturno S.C. Society (who provided the athletes).

\section{Results and discussion}

For each athlete a Formetric Postural Check Up was charted. This includes a 3D reconstruction of the surface torso and the individualization of specific postural parameters. ${ }^{89}$ From a detailed analysis of observed data it is noted that the values of the kyphotic curve for the Guillet athlete are much higher than normal (should be less than $40^{\circ} \mathrm{C}$ ) with a (red) alteration of the pelvic inclination, anteroposterior flexion with lateral deviation and left lateral flexion (Table 1) (Table 2). This athlete, after an analysis of her pain measurement form, has claimed that she does not feel rachis pain. Moreover, her performances are steadily at average/good levels. Considering the data collected for the other athletes, we can say that the values are covered by the standard. For example Valkay feels pain. As we can see in the table, she does not show irregular values, except for a slighty marked kyphotic curve ${ }^{10}$ (Figures 1-9).

Table I Summary of the data collected

\begin{tabular}{|c|c|c|c|c|c|c|c|c|c|}
\hline Surname & $\begin{array}{l}\text { Kyphosis } \\
\text { angle }\end{array}$ & $\begin{array}{l}\text { Lordosis } \\
\text { angle }\end{array}$ & $\begin{array}{l}\text { Pelvic } \\
\text { inclination } \\
\text { right }(\mathrm{Mm})\end{array}$ & $\begin{array}{l}\text { Pelvic } \\
\text { inclination } \\
\text { left }(\mathbf{M m})\end{array}$ & $\begin{array}{l}\text { Antero- } \\
\text { posterior } \\
\text { bending }\left({ }^{\circ}\right)\end{array}$ & $\begin{array}{l}\text { Lateral } \\
\text { deviation } \\
(\mathrm{Mm})\end{array}$ & $\begin{array}{l}\text { Lateral } \\
\text { bending } \\
\text { right }(\mathrm{Mm})\end{array}$ & $\begin{array}{l}\text { Lateral } \\
\text { bending } \\
\text { left }(\mathbf{M m})\end{array}$ & $\begin{array}{l}\text { Surface } \\
\text { rotation } \\
\left(^{\circ}\right)\end{array}$ \\
\hline Valkai & 47,50 & 46,80 & 0,00 & 0,00 & 1,30 & 6,40 & 4,50 & & 2,80 \\
\hline Pellegrino & 48,20 & 26,60 & 3,00 & & 5,30 & 3,20 & & 4,50 & 2,70 \\
\hline
\end{tabular}


Table Continued....

\begin{tabular}{|c|c|c|c|c|c|c|c|c|c|}
\hline Surname & $\begin{array}{l}\text { Kyphosis } \\
\text { angle }\end{array}$ & $\begin{array}{l}\text { Lordosis } \\
\text { angle }\end{array}$ & $\begin{array}{l}\text { Pelvic } \\
\text { inclination } \\
\text { right }(\mathrm{Mm})\end{array}$ & $\begin{array}{l}\text { Pelvic } \\
\text { inclination } \\
\text { left }(\mathbf{M m})\end{array}$ & $\begin{array}{l}\text { Antero- } \\
\text { posterior } \\
\left.\text { bending( }{ }^{\circ}\right)\end{array}$ & $\begin{array}{l}\text { Lateral } \\
\text { deviation } \\
(\mathrm{Mm})\end{array}$ & $\begin{array}{l}\text { Lateral } \\
\text { bending } \\
\text { right }(\mathrm{Mm})\end{array}$ & $\begin{array}{l}\text { Lateral } \\
\text { bending } \\
\text { left }(\mathbf{M m})\end{array}$ & $\begin{array}{l}\text { Surface } \\
\text { rotation } \\
\left({ }^{\circ}\right)\end{array}$ \\
\hline Masciandaro & 49,50 & 45,70 & 1,50 & & $\mathrm{I}, 00$ & 2,60 & & 12,00 & 6,10 \\
\hline Ciampichetti & 52,80 & 29,10 & 0,00 & 0,00 & 4,50 & $\mathrm{I}, 60$ & & 7,50 & $\mathrm{I}, 80$ \\
\hline Starace & 59,20 & 42,00 & 0,00 & 0,00 & 3,80 & 3,00 & 8,20 & & 3,30 \\
\hline Ciccariello & 57,80 & 46,10 & 0,00 & 0,00 & 0,40 & 5,90 & $\mathrm{I}, 80$ & & 4,00 \\
\hline Giuliani & 60,40 & 47,50 & & 9,00 & 4,40 & 3,50 & & 12,00 & 4,10 \\
\hline Guillet & 61,00 & 41,10 & & 12,00 & 5,80 & 10,70 & 9,00 & & 3,60 \\
\hline De simone & 53,40 & 64,00 & & 3,00 & 1,90 & 4,50 & $\mathrm{I}, 50$ & & 3,00 \\
\hline Ventriglia & 58,50 & 52,10 & & 3,00 & 0,70 & 6,90 & & 19,50 & 2,90 \\
\hline Di monaco & 53,40 & 49,60 & 3,00 & & 2,50 & 7,50 & & 13,50 & 2,10 \\
\hline
\end{tabular}

Table 2 \& 3 Linear regression

\begin{tabular}{|c|c|c|c|c|c|c|c|c|c|}
\hline Cognome & ETA & Angolo Cifosi & $\mathbf{X y}$ & $\times 2$ & $\mathbf{Y} 2$ & $\mathbf{Y}^{\prime}$ & $\mathbf{E}$ & $E^{\wedge} 2$ & $(Y-M)^{\wedge} 2$ \\
\hline Valkai & 33 & 47,50 & 1567,5 & 1089 & 2256,25 & $4,070,805$ & $-359,58$ & I29298, I & $5,430,556$ \\
\hline Pellegrino & 18 & 48,20 & 867,6 & 324 & 2323,24 & $2,220,439$ & $-173,84$ & 30221,7 & $4,447,864$ \\
\hline Masciandaro & 25 & 49,50 & 1237,5 & 625 & 2450,25 & $3,083,943$ & $-258,89$ & 67026,27 & $2,882,864$ \\
\hline Ciampichetti & 20 & 52,80 & 1056 & 400 & 2787,84 & $2,467,155$ & $-193,92$ & 37603,2 & $4,281,716$ \\
\hline Anastasio & 24 & 55,00 & 1320 & 576 & 3025,00 & $2,960,585$ & $-241,06$ & 58109,22 & 0,017101 \\
\hline Ciccariello & 24 & 57,80 & 1387,2 & 576 & 3340,84 & $2,960,585$ & $-238,26$ & 56767,13 & $8,589,408$ \\
\hline Giuliani & 32 & 60,40 & 1932,8 & 1024 & 3648,16 & $3,947,447$ & $-334,34$ & III I86,4 & $3,058,941$ \\
\hline Guillet & 28 & 61,00 & 1708 & 784 & 3721,00 & $3,454,016$ & $-284,40$ & 80884,29 & $3,758,633$ \\
\hline Stellato & 22 & 56,60 & 1245,2 & 484 & 3203,56 & 271,387 & $-214,79$ & 46133,45 & $2,995,562$ \\
\hline Ventriglia & 23 & 58,50 & 1345,5 & 529 & 3422,25 & $2,837,228$ & $-225,22$ & 50725,3 & $1,318,249$ \\
\hline Di Monaco & 17 & 53,40 & 907,8 & 289 & 2851,56 & $2,097,081$ & $-|56,3|$ & 24432,23 & $2,158,639$ \\
\hline Somma & 321 & 713,30 & $|769|, 9$ & 8237 & 39386,15 & & & 856334,5 & $2,479,277$ \\
\hline Media & $2,469,230,769$ & $548,692,308$ & & & & & & & \\
\hline
\end{tabular}

$\begin{array}{ll}\text { XY } & \text { Product of Variables } \\ X^{\prime} 2 & \text { Square of Variable } X \\ Y^{\prime} 2 & \text { Square of Variable } Y \\ Y^{\prime} & \text { State of } X \\ & \text { Diff. between our Valued Yarn and which was } \\ \text { e } & \text { Recommended with Regression Parameters } Y^{\prime} \\ \mathrm{e}^{\wedge 2} & \text { Sum of Square Errors } \\ (\mathrm{Y}-\mathrm{M})^{\wedge} 2 & \text { Proportion of Spare Parts } \\ & \text { Slope }=\mathrm{b}=0.2538 \text { I I } 88 \\ & \text { Intercept }=\mathrm{a}=48.6020297\end{array}$

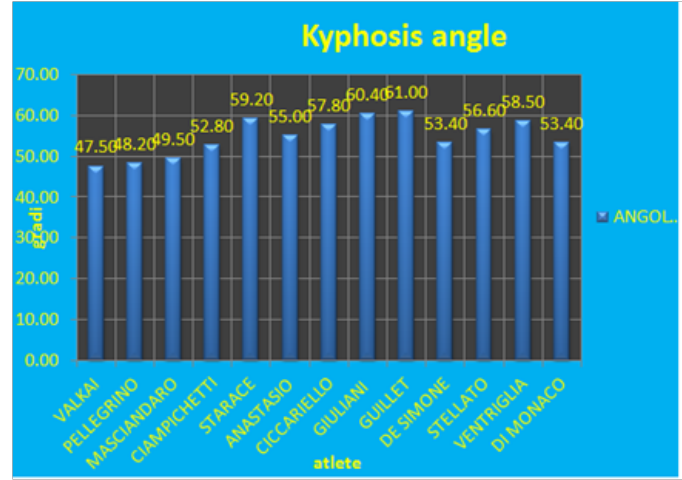

Figure I Kyphosis angle.

Citation: Napolitano S,Ascione A.Analysis of posture and its impact on performance in women's water polo. Open Access J Sci. 20 I7; I (3):9I-95. DOI: 10.15406/oajs.2017.01.00018 


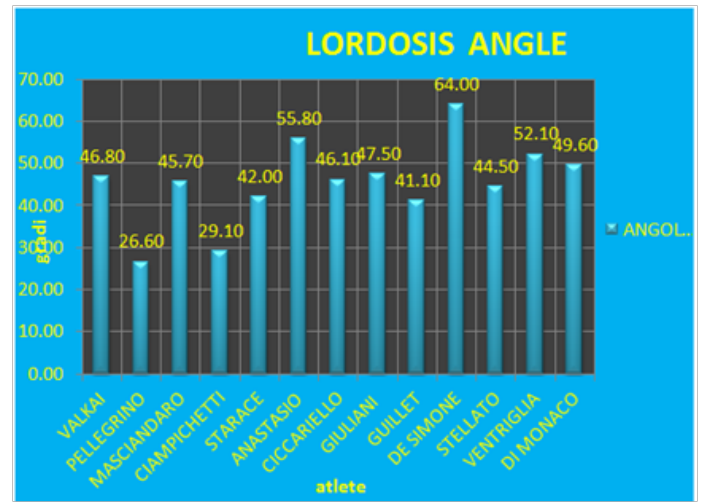

Figure 2 Lordosis corner.

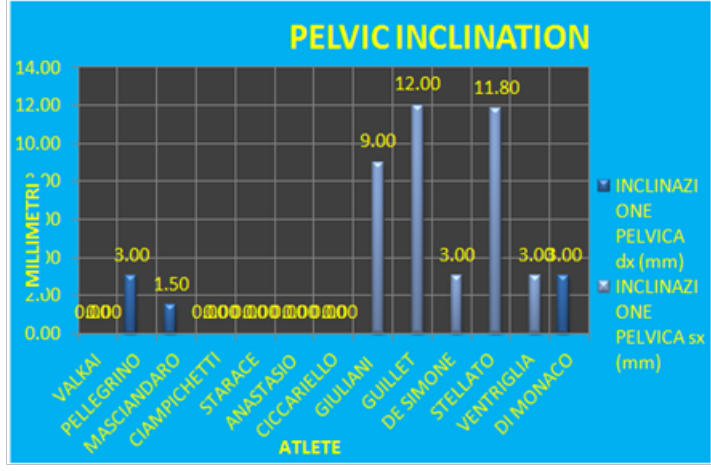

Figure 3 Pelvic inclination.

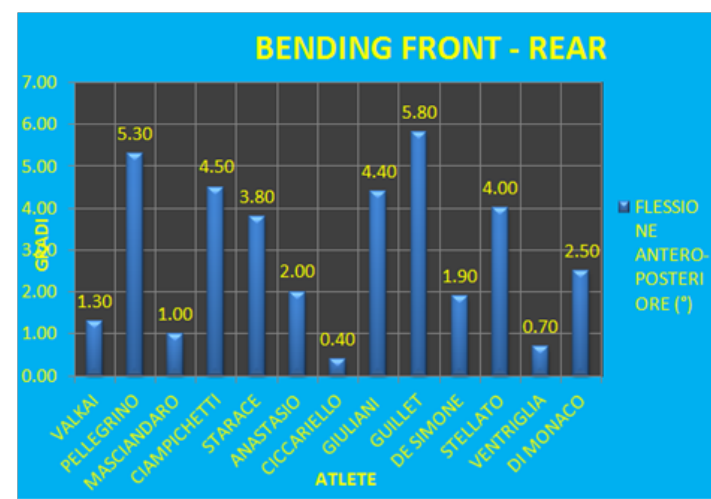

Figure 4 Bending front -rear.

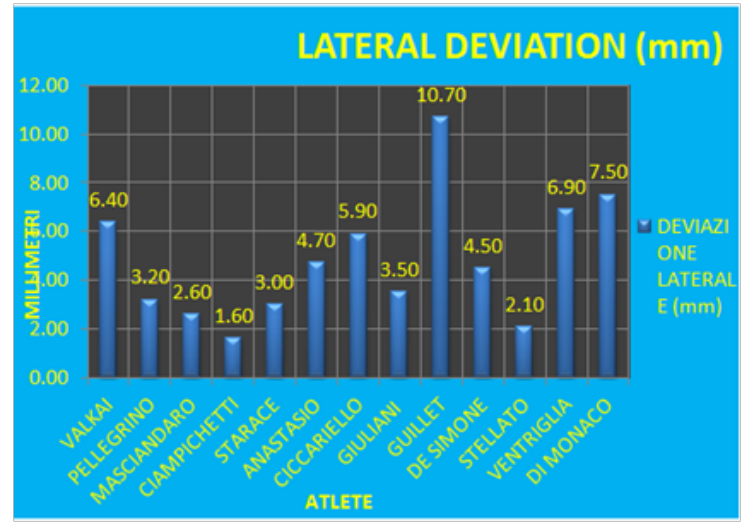

Figure 5 Lateral deviation.

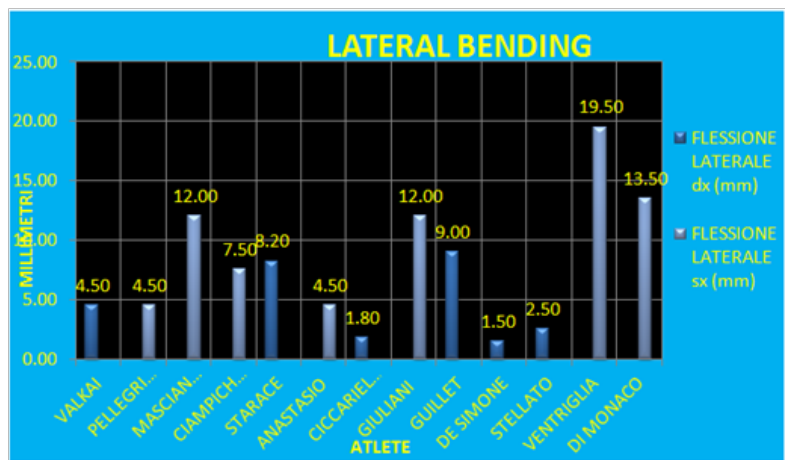

Figure 6 Lateral bending.

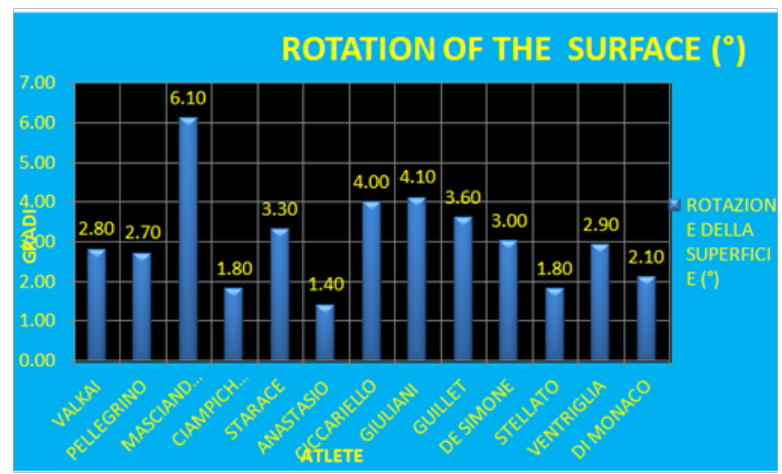

Figure 7 Rotation of the surface.

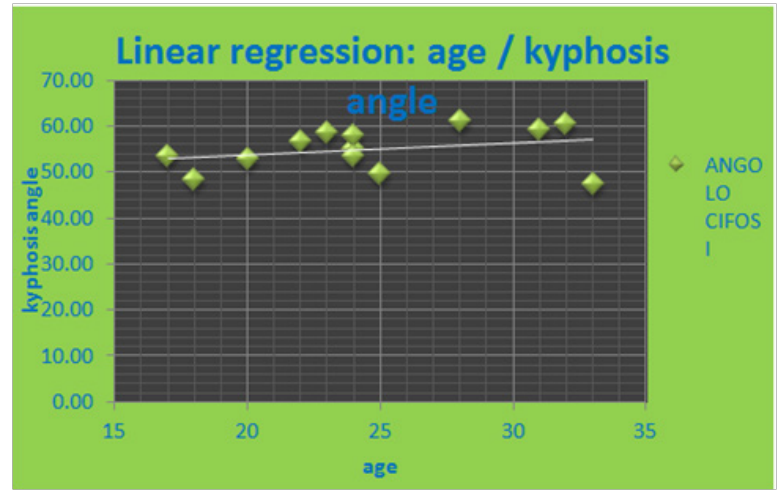

Figure 8 Linear regression.

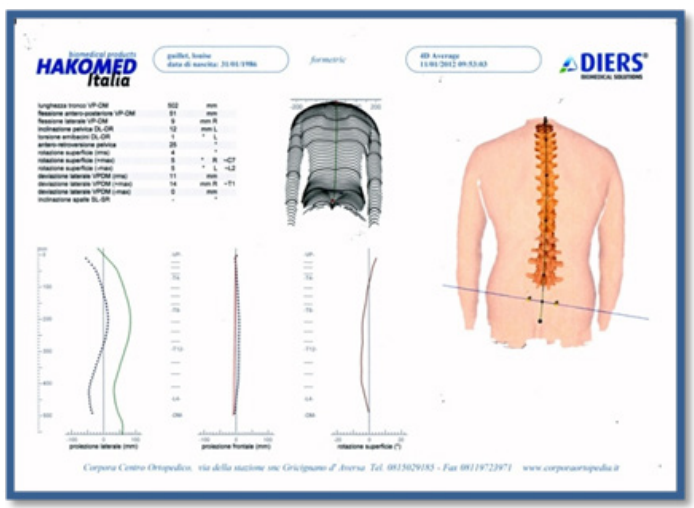

Figure 9 This includes a 3D reconstruction of the surface torso and the individualization of specific postural parameters. 


\section{Conclusion}

After careful evaluation of the observed data, we can state that there is no direct link between pain, performance and posture wrong. We have also to underline that this sport is practiced in the water so the up thrust, that is equal to the force of gravity, facilitates the support of the body. The human body can adapt in a morpho-functional and compensatory way but we cannot deny that a prolonged wrong posture can damage the good health of the athletes especially at the end of their sport careen.

\section{Acknowledgements}

None.

\section{Conflict of interest}

The authors declare that there is no conflict of interest

\section{References}

1. Ángyán L, Téczely T. Investigation of postural stability, reaction time and body measures in basket ball players. 2006.

2. Tursi D, Napolitano S, Raiola G. Assessment the technical execution in archery through video analysis. Buletin Stiintific-Universitatea din Pitesti. Seria Educatie Fizicasi Sport. 2013;17:41-43.
3. Napolitano S, Di Tore PA, De Miro C, et al. Technical Analysis in High Diving. Buletin Stiintific-Universitatea din Pitesti. Seria Educatie Fizicasi Sport. 2012;16:96-99.

4. Napolitano S. Cliff diving: water impact and video-analysis. Journal of Physical Education and Sport. 2014;14(1):93-97.

5. Tursi D, Napolitano S, Di Tore PA, et al. Evaluation of Incidence of ball handling on swimming intensity in female water polo. Buletin StiintificUniversitatea din Pitesti. Seria Educatie Fizicasi Sport. 2012;16:99-103.

6. Tursi D, Napolitano S, Raiola G. Assessment the technical execution in archery through video analysis. Buletin Stiintific - Universitatea din Pitesti. Seria Educatie Fizicasi Sport. 2013;17:41-43.

7. Napolitano S, Tursi D. The Assessment of the tactic in women's water polo: the experience of a team in the Italian championship premier league. Buletin Stiintific-Universitatea din Pitesti. Seria Educatie Fizica si Sport. 2013;17:36-40.

8. Raiola G, Parisi F, Napolitano S. Sports skills in youth volleyball by video analysis teaching method. Procedia: social \& behavioral sciences. 2014;117:436-441.

9. Tursi D, Napolitano S, Raiola G. Assessment the technical execution in archery through video analysis. Buletin stiintific - universitatea din pitesti. Seria educatie fizica si sport. 2013;17:41-43.

10. Napolitano S, Di Tore PA, De Miro C, et al. Technical analysis in high diving. Buletin stiintific-universitatea din pitesti. Seria educatie fizica si sport. 2012;16:96-99. 